\title{
Effects of intensified insulin treatment on retinal vessels in diabetic patients
}

\author{
O BRINCHMANN-HANSEN' K DAHL-JØRGENSEN, ${ }^{2} \mathrm{~K}$ F HANSSEN, ${ }^{3}$ \\ AND L SANDVIK ${ }^{4}$
}

From the 'Department of Ophthalmology, Ullevål University Hospital; the ${ }^{2}$ Department of Paediatrics, Aker University Hospital; the ${ }^{3}$ Department of Medicine B Aker University Hospital; and the ${ }^{\star}$ Medstat, Oslo, Norway

SUMmARY Forty-five diabetic patients were randomly assigned to treatment with continuous subcutaneous insulin infusion (CSII), multiple injections (MI), and conventional insulin treatment (CIT). They were prospectively followed up for one year. A computerised scanning microdensitometer was applied on fundus photographs of retinal vessels, and we studied changes in calibres of the blood column $\left(W_{0}\right)$ and in width $\left(W_{r} / W_{0}\right)$ and intensity $\left(I_{r}\right)$ of the central 'light reflex'. After six months of improved metabolic control the $\mathrm{I}_{\mathrm{r}}$ was reduced in both $\mathrm{MI}$ and CSII cases compared with CIT cases $(p<0 \cdot 01)$, indicating haemorrheological changes in the retinas. Within these six months cotton-wool spots appeared in half the patients $(n=15)$ on CSII and MI, but not in CIT patients. Subjects who developed cotton-wool spots, compared with those who did not, had greater intensities of reflection and larger calibres of vessels at the start of the study $(p<0 \cdot 01)$. On intensifying the treatment they were characterised by a larger fall in hemoglobin $A_{1}(p<0.01)$ and by a larger decrease in $I_{r}$ on arteries $(p<0.05)$ and veins $(p<0.01)$. The behaviour of the retinal circulation is different in patients developing transient ischaemic lesions on intensified insulin treatment from its behaviour in those who do not.

A worsening of diabetic retinopathy has been observed when intensified treatment by continuous subcutaneous insulin infusion is initiated. ${ }^{1-5}$ The transient appearance of cotton-wool spots (soft exudates), considered to represent signs of ischaemia, was a prominent feature of these changes. The pathogenetic cause is not known, but a haemodynamic model of explanation has been suggested by various authors: a rapid change toward normo- or hypoglycaemia might reduce the blood flow to insufficient levels of perfusion. ${ }^{1-3 \leqslant-7}$

Adjustments of calibre of arteries and veins are part of the autoregulatory mechanisms responsible for a constant blood flow to the retina. ${ }^{89}$ Increased blood flow 1111 and vasodilatation ${ }^{12}$ have been found in acute hyperglycaemia, and increased flow ${ }^{13-16}$ and vasodilatation $^{(1-2)}$ have been registered in diabetic patients. Whether the circulatory changes are related to hyperglycaemia per se and/or to other factors of

Correspondence to Olaf Brinchmann-Hansen, MD, Department of Ophthalmology, Ullevål University Hospital, Kirkeveien 166, 0407 Oslo 4, Norway. the disease is not clear. It seems most important to clarify vascular retinal reactivity to variations in both acute and long-term changes in metabolic control.

In a prospective and randomised trial insulin dependent diabetic patients in the Oslo Study, ${ }^{+5}$ were assigned to either continuous subcutaneous insulin infusion, multiple injections, or to conventional insulin treatment. By means of a computerised microdensitometric technique on fundus photographs $^{2122}$ we studied the calibre of retinal vessels during one year of strict glucose control. This technique also measured the central 'light reflex', which represents the light reflected from the streaming column of erythrocytes. This reflex is of circulatory interest. It has been shown that the intensity of reflection in arteries and veins and the width of the reflex in veins are significantly lower in diabetic patients than in normal controls. ${ }^{23}$ The effect of near normoglycaemia on this reflex was examined. Further, we identified some vascular characteristics in patients at risk of developing cotton-wool spots during exposure to rapidly improved metabolic control. 
Table 1 Clinical characteristics after randomisation to three treatment groups (mean and range)

\begin{tabular}{|c|c|c|c|c|c|c|c|}
\hline $\begin{array}{l}\text { Treatment } \\
\text { groups }\end{array}$ & $\begin{array}{l}\text { Sex } \\
(M / F)\end{array}$ & $\begin{array}{l}\text { Age } \\
\text { (years) }\end{array}$ & $\begin{array}{l}\text { Duration } \\
\text { (months) }\end{array}$ & $\begin{array}{l}H b A_{1} \\
(\%)\end{array}$ & $\begin{array}{l}\text { Systolic BP } \\
\text { (mm Hg) }\end{array}$ & $\begin{array}{l}\text { Diast. BP } \\
\text { (mınHg) }\end{array}$ & $\begin{array}{l}I O P^{*} \\
(\mathrm{mmHg})\end{array}$ \\
\hline $\operatorname{CIT}(n=15)$ & $7 / 8$ & $26(18-36)$ & $152(81-240)$ & $9 \cdot 5(7 \cdot 6-14 \cdot 6)$ & $125(110-150)$ & $78(70-95)$ & $13 \cdot 1(9-19)$ \\
\hline $\operatorname{MI}(n=15)$ & $7 / 8$ & $26(19-42)$ & $154(81-250)$ & $9 \cdot 4(7 \cdot()-11 \cdot 7)$ & $124(110-140)$ & $80(60)-95)$ & $13 \cdot 2(9-18)$ \\
\hline $\operatorname{CSII}(n=15)$ & $7 / 8$ & $26(18-38)$ & $153(77-280)$ & $10 \cdot 1(8 \cdot(1-12 \cdot 9)$ & $123(110-160)$ & $81(70-100)$ & $13 \cdot 0(9-18)$ \\
\hline
\end{tabular}

*Mean value of both eyes.

\section{Subjects and methods}

\section{SUBJECTS}

Forty-five insulin dependent diabetic patients (the Oslo Study ${ }^{+5}$ ) were included. The clinical characteristics, the inclusion criteria, and the randomisation procedure have previously been presented in detail. ${ }^{5}$ In summary, the patients were randomly, at time 0 , divided into three treatment groups: CIT: conventional insulin treatment ( 2 daily insulin injections); MI: multiple insulin injections (4-6 times daily); and CSII: continuous subcutaneous insulin infusion. To balance the groups, computerised matching was performed. It was based on the following criteria: sex, age, diabetes duration, metabolic control (Table 1 ), and retinopathy (grade 1, no retinopathy; grade 2 , one to three microaneurysms or haemorrhages; grade 3 , more than three microaneurysms or haemorrhages; and grade 4, grade 3 plus hard exudates). Patients with proliferative retinopathy were not included. The one eye (denoted the primary eye) with the best visual acuity or the smallest refractive error, or both, was selected for vessel measurements. One eye was selected at random if no differences were found. Visual acuities were 20/20 in all primary eyes, and the range of refractory errors was from +0.5 to -4.0 dioptres with a mean of -0.8 dioptres.

\section{OPHTHALMIC EXAMINATIONS}

All examinations relevant to this study were performed two months before randomisation (preperiod), at the time of randomisation (time 0 ), and 3,6 , and 12 months later. The examinations included fundus photography of both eyes and fluorescein angiography of the primary eye. Furthermore, both eyes were scrutinised for cotton-wool spots by indirect ophthalmoscopy and binocular microscopy.

BLOOD PRESSURE AND INTRAOCULAR PRESSURE Diastolic and systolic blood pressure and intraocular pressure were registered shortly before and shortly after fundus photography, respectively. The intraocular pressure was measured in cycloplegia. This was done to obtain pressures as representative as possible of the state of the eye at the moment of fundus photography (for comparable vessel measurements). Comparable results of mean values and ranges were obtained in the three treatment groups (Table 1).

\section{METABOLIC CONTROL}

Haemoglobin $A_{1}$ was estimated by an agar gel electrophoresis method..$^{-4}$ Mean blood glucose values were calculated by weekly capillary blood sampling on filter paper" ${ }^{35}$ before and 90 minutes after each meal, at bedtime, and in the morning. In a twomonth preperiod home monitoring of blood glucose was introduced. Metabolic control was estimated at the same time intervals as described for the ophthalmic examinations. Blood glucose was also determined at exactly the same time as photography of the fundus.

\section{METHODS}

Densitometry across vessels in fundus photographs has been found to be an objective and sensitive method of measuring calibre. ${ }^{26}{ }^{27}$ Our photographic ${ }^{22}$ and computerised microdensitometric ${ }^{21}$ techniques have recently been described elsewhere. A short summary is presented here.

A $30^{\circ}$ 'standard' fundus photograph of the primary eye was produced by centring the photograph at onehalf the distance between the fovea and the temporal edge of the optic disc. An interference filter with a maximum transmission peak at $535 \mu \mathrm{m}$ was inserted in the light path of the Zeiss camera, and a $35 \mathrm{~mm}$ Kodak Plus-X panchromatic type 5062 film was used. A 48-step density wedge was photographed and developed together with each film. A true calibration for transformation from film density into a linear intensity scale was obtained. The measured widths presented in this paper are expressed as micrometers $(\mu \mathrm{m})$ on the retina.

In each photograph three arteries and three veins were analysed. We selected vessels having a straight course in the retina and chose the largest and two middle-sized vessels. Using a Nikon profile projector and anatomical landmarks in the pictures, we selected specific sites on the vessels and marked them directly on the negatives. Since we studied both the calibre and the light reflex, we did not use the 
Fig. 1 A typical scan profile across a retinal vessel showing the background retina, the vessel absorption, $I_{0}$, and the central light reflex. $I_{0}$ is measured from an average background intensity level, $\left(I_{\max }\right)$, and the width of the blood column, $W_{0}$, is measured at half minimum intensity of $I_{0}$. The width of the light reflex, $W_{\mathrm{r}}$, is measured at half maximum intensity of the peak intensity of the reflex, $I_{\mathrm{r}}$. (From Brinchmann-Hansen and Engvold. ${ }^{21)}$

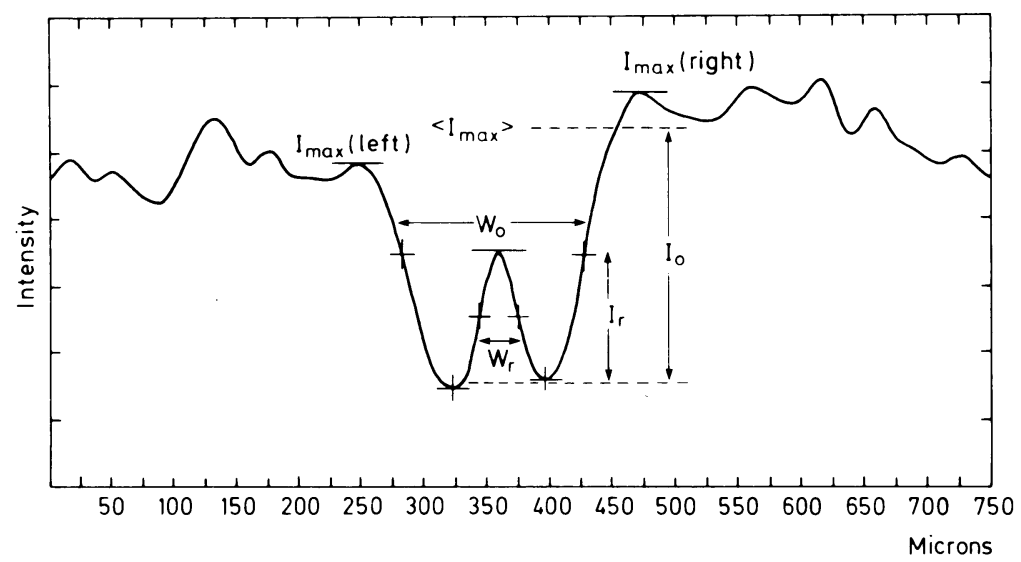

fluorescein angiograms for measurements. The fluorescein technique does not produce central light reflexes.

We used a computer controlled microphotometer (a $288 \mathrm{~K}$ memory HP-21MX computer and a Heidenhain optical encoder) for scanning across the vessels and for data processing. The positional accuracy of the instrument was better than $1 \mu \mathrm{m}$. The scan contained 512 or 1024 data points, the scanning aperture was $5 \mu \mathrm{m}$ wide (in the scanning direction), and the height mostly used was $250 \mu \mathrm{m}$. The microphotometry data were read from the magnetic tapes, converted from film transmission to relative intensity, and viewed with a display unit.

A typical scan profile is shown in Fig. 1. By means of a cross-hair cursor the background intensity levels were chosen on either side of the vessel and the other parameters were then derived by the computer. The depth of the vessel absorption relative to the average retinal background $\left(\mathrm{I}_{0}\right)$ was measured. The width of the vessel, $W_{0}(=$ the red blood cell column), was determined at the full width of the vessel absorption at half minimum intensity of $I_{0}$. The width of the light reflex $\left(W_{r}\right)$ is measured at half maximum intensity of the peak intensity of the reflex, $I_{r}$. The ratio of the widths, $W_{r} / W_{0}$, is used in this study, and the $I_{r}$ is expressed as relative values. The fundus photography was not synchronised to pulse characteristics, but the randomly exposed pictures should not give any systematic errors.

\section{STATISTICS}

A two-sided Wilcoxon rank sum test was used to compare mean values in different treatment groups, and a two-sided Wilcoxon signed rank test to compare means within the same group. A two-sided Fisher-Irwin exact test was used to compare frequencies. The level of significance was set at $5 \%$. In calculating correlations between calibre of vessels and various clinical characteristics in the 45 patients, the non-parametric Kendall's $\tau$ method was used. ${ }^{28}$

\section{Results}

\section{RETINOPATHY}

The changes in retinopathy have previously been published. ${ }^{5}$ A masked quantitative evaluation of colour fundus photographs (both eyes) showed a transient increase in number of microaneurysms and haemorrhages after three months' treatment by CSII. Masked ranking of fluorescein angiograms (primary eyes) showed a progressive deterioration on CIT, no changes on MI, and a transient worsening at three months on CSII.

During six months' treatment eight patients on MI and seven on CSII had developed cotton-wool spots in either one or both eyes. No cotton-wool spots were seen in patients on CIT, and no new spots developed at 12 months in any of the treatment groups. Patients developing cotton-wool spots $(n=15)$ were characterised by a longer duration of diabetes and by more retinopathy at the start of the study than patients without cotton-wool spots on MI and CSII. ${ }^{5}$ No age differences were noted (mean \pm SEM) in subjects developing cotton-wool spots, $26 \cdot 3 \pm 1 \cdot 3$ years compared with subjects without cotton-wool spots, $26 \cdot 0 \pm 2 \cdot 0$ years.

BLOOD PRESSURE AND INTRAOCULAR PRESSURE No significant differences or changes in these parameters were found between treatment groups, between subjects with and without cotton-wool spots, or within each group throughout the study.

\section{METABOLIC CONTROL}

In the two months before treatment a lowering of haemoglobin $A_{1}$ was found in all treatment groups $(p<0.01)$ (Fig. 2). After three months' treatment 

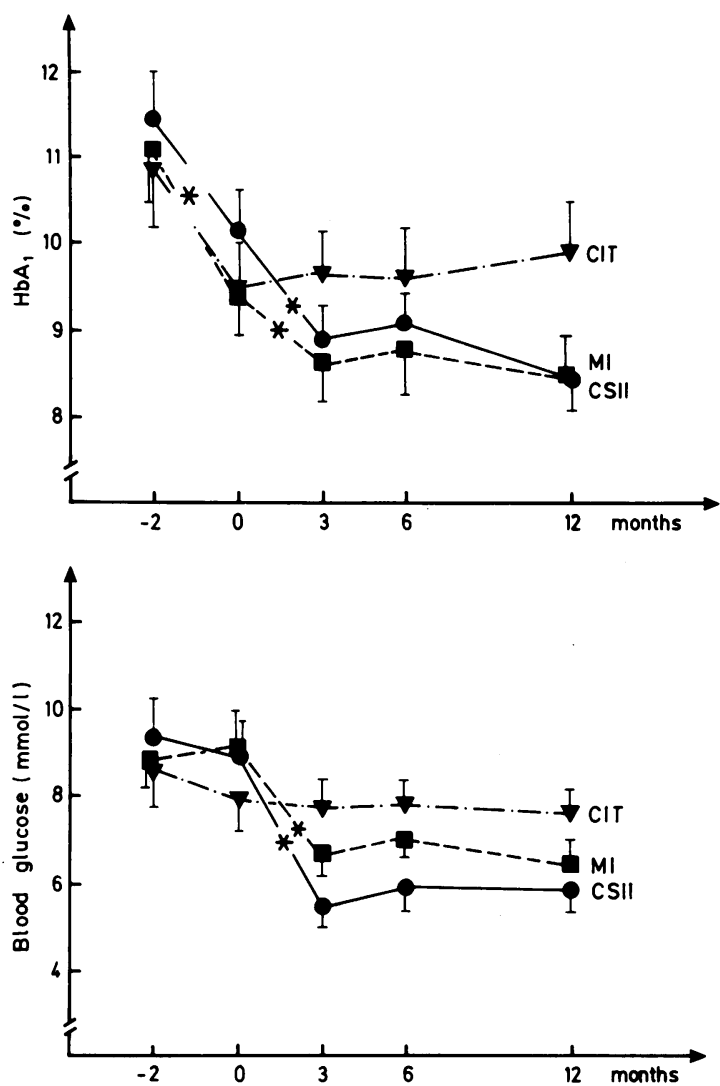

Fig. 2 Metabolic control through the course of the study. Mean values; vertical bars: SEM. Decrease from preceding value within the treatment groups: ${ }^{*}$ denotes $p<0 \cdot 01$. The improved metabolic control between 3 and 12 months is statistically significant. $H b A_{1}: C I T$ vs $M I(p<0.05)$ and CIT vs CSII $(p<0.01)$. Blood glucose: CIT vs MI $(p<0.01)$ and CIT vs CSII $(p<0 \cdot 01)$.

significant reductions in haemoglobin $A_{1}$ and mean blood glucose values were found in the MI and the CSII groups $(p<0 \cdot 01)$, but not in the CIT group. The difference in improved control between intensified regimens and conventional treatment was sustained from 3 to 12 months treatment.

At three months patients developing cotton-wool spots had a greater decrease in haemoglobin $A_{1}$ $(-3 \cdot 3 \pm 0 \cdot 5$ and $-1 \cdot 3 \pm 0 \cdot 5)$ and mean blood glucose $(-3 \cdot 6 \pm 0 \cdot 5$ and $-1 \cdot 6 \pm 0 \cdot 6)$ than those on MI and CSII treatment who did not $(\mathrm{p}<0 \cdot 01)$.

CALIBRE OF VESSELS ( $\left.w_{0}\right)$

In the 45 subjects at the start of the preperiod a positive correlation between calibre of veins and the age of the patients $(\tau=0.32 ; p<0.05)$ and a negative correlation between calibre of veins and the diastolic
Table 2 Correlations between mean calibre of retinal vessels and various clinical characteristics in the 45 diabetics at the start of the study (Kendall's $\tau^{*}$ )

\begin{tabular}{llc}
\hline Clinical parameters & \multicolumn{2}{l}{ Mean calibre } \\
\cline { 2 - 3 } & Arteries & Veins \\
\hline Sex & - & - \\
Age & - & $0 \cdot 32$ \\
Duration of disease & - & - \\
HbA $_{1}$ & - & - \\
Blood glucose value $\dagger$ & - & - \\
Systolic blood pressure & - & $-0 \cdot 21$ \\
Diastolic blood pressure & - & - \\
Intraocular pressure & - & - \\
Retinopathy grading & - & \\
\hline
\end{tabular}

*The coefficient $(\tau)$ is presented when present on a statistical significant level of $p \leqslant 0 \cdot 05$-corresponding to a $\tau$ value of $\geqslant 0 \cdot 20$. $\dagger$ Determined at the instant of calibre measurements.

-: not significant.

$(\tau=-0.26 ; p<0 \cdot 05)$ and the systolic $(\tau=-0 \cdot 21$; $\mathrm{p}<0.05$ ) blood pressure were found (Table 2 ).

The distribution of calibre measurements in the three treatment groups at the start of the study is shown in Table 3. Comparable mean values and ranges of $\mathrm{W}_{0}$ between groups were found. No changes in retinal arteries and veins were found in the treatment groups during the course of the study (Table 3).

In patients on MI and CSII those with cotton-wool spots were characterised by having greater initial calibre of retinal arteries $(p<0.01)$ and veins $(p<0.001)$ than patients without cotton-wool spots (Fig. 3). Among subjects having an average vein diameter $\geqslant 140 \mu \mathrm{m}$ eight of $10(80 \%)$ developed cotton-wool spots, compared with seven out of 18 $(39 \%)$ in subjects with diameter of $<140 \mu \mathrm{m}$. Although a significant long-term improvement in metabolic control was obtained, especially in patients with cotton-wool spots, no changes in either arteries

Table 3 The calibre of retinal vessels during the course of the study (mean $\pm S E M$ )

\begin{tabular}{|c|c|c|c|c|c|}
\hline & \multicolumn{5}{|l|}{ Months } \\
\hline & -2 & 0 & 3 & 6 & 12 \\
\hline \multicolumn{6}{|c|}{ Arteries $W_{0}(\mu \mathrm{m})^{*}$ : } \\
\hline CIT $(n=15)$ & $114 \pm 4$ & $109 \pm 4$ & $114 \pm 4$ & $115 \pm 5$ & $112 \pm 5$ \\
\hline MI $(n=15)$ & $116 \pm 4$ & $115 \pm 3$ & $116 \pm 4$ & $113 \pm 7$ & $117 \pm 6$ \\
\hline $\operatorname{CSII}(n=15)$ & $116 \pm 4$ & $118 \pm 4$ & $116 \pm 4$ & $116 \pm 4$ & $113 \pm 4$ \\
\hline \multicolumn{6}{|c|}{ Veins $W_{0}(\mu \mathrm{m})^{*}:$} \\
\hline CIT $(n=15)$ & $129 \pm 6$ & $125 \pm 4$ & $135 \pm 7$ & $132 \pm 5$ & $129 \pm 6$ \\
\hline MI $(n=15)$ & $133 \pm 8$ & $127 \pm 8$ & $131 \pm 9$ & $134 \pm 9$ & $133 \pm 8$ \\
\hline $\operatorname{CSII}(n=15)$ & $131 \pm 4$ & $132 \pm 6$ & $132 \pm 5$ & $131 \pm 6$ & $129 \pm 6$ \\
\hline
\end{tabular}

${ }^{*}$ Mean values of three arteries and three veins in each patient. 
or veins were observed during 12 months of treatment (Fig. 3).

\section{LIGHT REFLEX $\left(\mathrm{w}_{\mathrm{r}} / \mathrm{W}_{0}\right.$ AND $\left.\mathrm{I}_{\mathrm{r}}\right)$}

No differences and no changes in the width of the reflex $\left(W_{r} / W_{0}\right)$ were found between the groups, in patients with and without cotton-wool spots or throughout the course of the study (Table 4). From randomisation to the end of six months' treatment a decrease in $I_{r}$ in the intensified regimens (MI and CSII) occurred in both arteries and veins $(p<0 \cdot 01)$.

At the start of the study $I_{r}$ in both arteries $(p<0.01)$ and veins $(p<0.01)$ was more intense in subjects on $\mathrm{MI} / \mathrm{CSII}$ developing cotton-wool spots than in those who did not (Fig. 4). Furthermore, subjects with cotton-wool spots were characterised by a greater increase in intensity during the preperiod in arteries $(p<0.05)$ and during the preperiod and after three
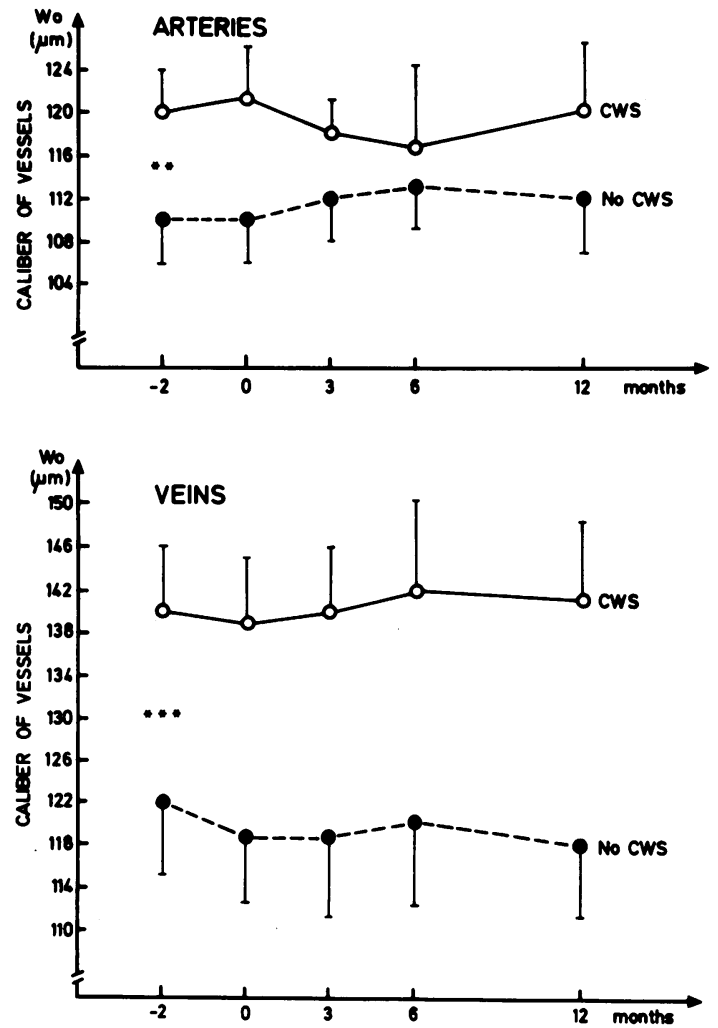

Fig. 3 Calibre of retinal vessels (mean of three arteries and three veins in each subject) through the course of the study. Pooled data on subjects on MI and CSII are used. Mean $\pm S E M$ in subjects with cotton-wool spots (CWS), $n=15$, and in subjects without (No CWS), $n=15$, are presented. Differences in initial size of vessels: ${ }^{* *}$ denotes $p<0.01$ and $^{* * *}$ denotes $p<0.001$. months of intensified treatment in veins $(\mathrm{p}<0.05)$. A significant decrease in $I_{r}$ was seen from three to six months in both arteries $(\mathrm{p}<0.05)$ and veins $(\mathrm{p}<0.01)$ in patients with cotton-wool spots.

\section{Discussion}

Increased retinal blood flow and vasodilatation may be important in the progression of diabetic retinopathy. ${ }^{24-34} \mathrm{~A}$ reversal of venous dilatation has been reported with improvement of metabolic control. ${ }^{35}$ We found, however, that the calibre of arteries and veins was unaffected by intensified insulin treatment, by significant lowering of blood glucose levels, and by slow progression (CIT) and transient (CSII) worsening in retinopathy. In agreement with our findings, Hickam and Frayser found no diameter changes in retinal vessels during glucose infusion in normal
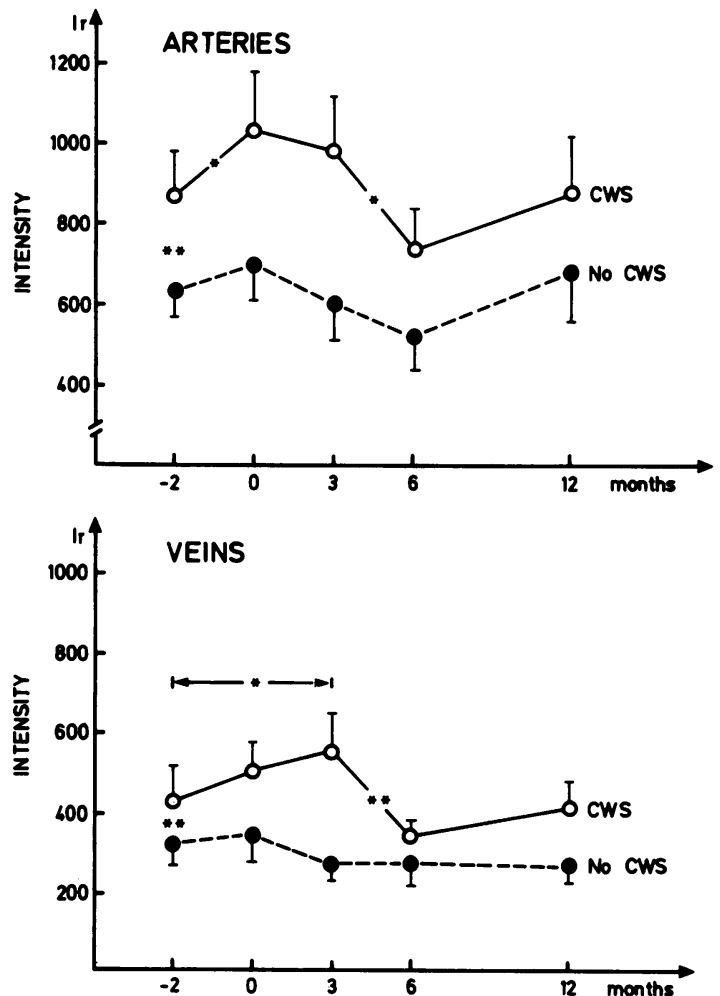

Fig. 4 The intensity of the light reflex $\left(I_{\mathrm{r}}\right)$ through the course of the study. Measurements derived from the same scans as used in Fig. 3. Mean $\pm S E M$ in subjects on MI/CSII with cotton-wool spots (CWS), $n=15$, and in subjects without (No $C W S), n=15$, are presented. Significant differences between $C W S$ and No CWS subjects at start and in CWS subjects from -2 to 6 months are denoted: ${ }^{*} p<0.05 ;{ }^{* *} p<0.01$. 
Table 4 The width $\left(W_{\mathrm{r}} / W_{0}\right)$ and the intensity $\left(I_{\mathrm{r}}\right)$ of the light reflexes during the course of the study (mean $\left.\pm S E M\right)$

\begin{tabular}{|c|c|c|c|c|c|}
\hline & \multicolumn{5}{|l|}{ Months } \\
\hline & -2 & 0 & 3 & 6 & 12 \\
\hline \multicolumn{6}{|c|}{ Width $\left(\mathrm{W}_{\mathrm{r}} / \mathrm{W}_{0}\right)^{*}$} \\
\hline \multicolumn{6}{|c|}{ Arteries } \\
\hline CIT & $0 \cdot 24 \pm 0 \cdot 02$ & $0.23 \pm 0.02$ & $0 \cdot 21 \pm 0 \cdot 01$ & $0 \cdot 23 \pm 0 \cdot 02$ & $0 \cdot 20 \pm 0 \cdot 01$ \\
\hline MI & $0 \cdot 22 \pm 0.01$ & $0.20 \pm 0.01$ & $0.23 \pm 0.02$ & $0 \cdot 20 \pm 0.01$ & $0 \cdot 20 \pm 0 \cdot 01$ \\
\hline CSII & $0 \cdot 19 \pm 0 \cdot 01$ & $0 \cdot 21 \pm 0.01$ & $0.21 \pm 0.01$ & $0 \cdot 19 \pm 0.01$ & $0 \cdot 19 \pm 0 \cdot 01$ \\
\hline \multicolumn{6}{|l|}{ Veins } \\
\hline CIT & $0 \cdot 19 \pm 0 \cdot 01$ & $0 \cdot 19 \pm 0 \cdot 01$ & $0 \cdot 17 \pm 0 \cdot 02$ & $0 \cdot 21 \pm 0 \cdot 01$ & $0 \cdot 19 \pm 0 \cdot 01$ \\
\hline MI & $0 \cdot 20 \pm 0 \cdot 02$ & $0 \cdot 18 \pm 0.02$ & $0 \cdot 17 \pm 0 \cdot 01$ & $0 \cdot 19 \pm 0 \cdot 02$ & $0 \cdot 18 \pm 0 \cdot 02$ \\
\hline CSII & $0 \cdot 17 \pm 0 \cdot 01$ & $0 \cdot 19 \pm 0.01$ & $0 \cdot 19 \pm 0 \cdot 02$ & $0 \cdot 19 \pm 0 \cdot 02$ & $0 \cdot 20 \pm 0.02$ \\
\hline \multicolumn{6}{|c|}{ Intensity $\left(I_{r}\right)^{*}$} \\
\hline \multicolumn{6}{|c|}{ Arteries } \\
\hline CIT & $704 \pm 86$ & $865 \pm 91$ & $744 \pm 65$ & $777 \pm 41$ & $667 \pm 67$ \\
\hline MI & $883 \pm 109$ & $1009 \pm 122$ & $894 \pm 109$ & $732 \pm 101 \dagger$ & $876 \pm 114$ \\
\hline CSII & $734 \pm 78$ & $825 \pm 116$ & $749 \pm 124$ & $564 \pm 88 \dagger$ & $709 \pm 109$ \\
\hline \multicolumn{6}{|l|}{ Veins } \\
\hline CIT & $404 \pm 61$ & $509 \pm 72$ & $412 \pm 37$ & $414 \pm 52$ & $394 \pm 41$ \\
\hline MI & $423 \pm 77$ & $422 \pm 70$ & $416 \pm 83$ & $304 \pm 51 \dagger$ & $331 \pm 58$ \\
\hline CSII & $362 \pm 45$ & $488 \pm 61$ & $442 \pm 69$ & $322 \pm 42 \dagger$ & $371 \pm 57$ \\
\hline
\end{tabular}

* Mean values of three arteries and three veins in each patient.

$\dagger$ Decrease from the start of randomisation (time 0): $p<0 \cdot 01$.

persons, ${ }^{36}$ and Kohner et al. found no correlations between blood sugar levels and retinal volume flow in diabetic patients. ${ }^{13}$

This study thus indicates that middle-sized and large vessels are unresponsive to long-term changes in blood glucose levels per se, at least at this particular level of retinopathy. This interpretation, however, is complicated by the fact that retinal vessels in diabetic retinopathy have a reduced reactivity to substances known to be vasoactive..$^{27} 37$ Furthermore, although correlations have been found between flow and calibre changes, ${ }^{39-41}$ some autoregulatory response may still have taken place. The small arterioles, which were not measured here, could have changed in diameter and affected the blood velocity.

Patients with the greatest diameters of retinal vessels seemed at risk of developing cotton-wool spots during intensified insulin treatment. We may speculate if diabetics with anatomically large arteries and veins are less capable of adapting to sudden metabolic and/or haemodynamic changes in the retina. Alternatively, patients developing cottonwool spots suffered the greatest degree of prestudy 'chronic' vasodilatation; the stretching of the walls would impair the ability of the vessels to adapt their size according to needs.

\section{LIGHT REFLEX OF THE VESSELS}

A previous study has shown that our 45 diabetics, compared with a non-diabetic group, had narrower widths of the reflex $\left(\mathrm{W}_{\mathrm{r}} / \mathrm{W}_{\mathrm{o}}\right)$ in the veins. ${ }^{23}$ In the present study return to nearly normal of the blood glucose did not 'normalise' the width. Favouring the intravascular blood column as the main reflecting surface producing the reflex, a recent theoretical study has shown that velocity/flow changes may influence the ratio $\mathrm{W}_{\mathrm{r}} / \mathrm{W}_{0} \cdot{ }^{42}$ Although this parameter is a rather coarse measure, it indicates that no significant haemodynamic changes occurred during the course of the study.

Physically, light reflection will occur only across surfaces of different refractive indices. Small changes in existing differences in indices between the streaming erythrocytes and the plasma of the retinal circulation may influence the intensity of the vascular reflex $\left(I_{r}\right){ }^{43}$ In comparison with normal controls, $I_{r}$ was found to be significantly reduced in both arteries and veins in the 45 participants at the start of the study. ${ }^{23}$ This could be explained by disturbances in the water shift from plasma to the erythrocytes ${ }^{44} 45$ and in the composition of plasma proteins and plasma viscosity $^{45-47}$ which are found in diabetes. Increased mean corpuscular volume (MCV), elevated levels of plasma proteins, and probably a reduced intravascular pressure would all lower the $\mathrm{I}_{\mathrm{r}}{ }^{23}$

Although the diameters of the streaming blood columns did not change, the intensity of the reflected light from these columns varied throughout the study. This indicates different intravascular effects of a rapid initial improved metabolic control (2-3 months) compared with a long-term (6-12 months) improved control. The association between changes in the intensity of the light reflex and changes in 
retinopathy indicates a role for haemorrheological factors in the progression of microangiopathy in diabetes. Local conditions in the eye (large vessels) might be of significance to the retinal response during tightening of the glucose control.

This study was supported by grants from the Norwegian Council on Cardiovascular Diseases, the Norwegian Heart and Lung Disease Association, the Norwegian Diabetes Association, the University of Oslo, the Norwegian Council for Science and the Humanities, and the Anders Jahres Medical foundation.

\section{References}

1 Lauritzen T, Frost-Larsen K, Deckert T, the Steno Study Group. Effect of 1 year of near-normal blood glucose levels on retinopathy in insulin-dependent diabetics. Lancet 1983; i: 200-4.

2 Van Ballegooie E, Hooymans JMM, Timmerman Z, et al. Rapid deterioration of diabetic retinopathy during treatment with continuous subcutaneous insulin infusion. Diabetes Care 1984; 7: 236-42.

3 The Kroc Collaborative Study Group. Blood glucose control and the evolution of diabetic retinopathy and albuminuria. $N$ Engl $J$ Med 1984; 311: 365-72.

4 Dahl-Jørgensen K, Brinchmann-Hansen O, Hanssen KF, Sandvik L, Aagenæs $\emptyset$, Aker Diabetes Group. Rapid tightening of blood glucose control leads to transient deterioration of retinopathy in insulin dependent diabetes mellitus: the Oslo Study. Br Med J 1985; 290: 811-5

5 Brinchmann-Hansen O, Dahl-Jørgensen K, Hanssen KF, Sandvik L, the Oslo Study Group. Effects of intensified insulin treatment on various lesions of diabetic retinopathy. $\mathrm{Am} \mathrm{J}$ Ophthalmol 1985; 100: 644-53.

$6 \mathrm{Keen} \mathrm{H}$. Normoglycaemic re-entry and diabetic complications. Diabetic Med 1984; 1: 85-7.

7 Canny CLB, Kohner EM, Trautman J, Puklin J, Morse P (for the Kroc Collaborative Study Group). Comparison of stereofundus photographs in patients with insulin-dependent diabetes during conventional insulin treatment or continuous subcutaneous insulin infusion. Diabetes 1985; 34 (suppl 3): 50-5.

8 Duke-Elder S, Gloster J. The vascular circulation. In: DukeElder S, ed. System of ophthalmology, The physiology of the eye and of vision. London: Kimpton, 1968; 4: 64-8.

9 Russel RWR. Evidence for autoregulation in human retinal circulation. Lancet 1973 ; ii: $1048-50$.

10 Atherton A, Hill DW, Keen H, Young S, Edwards EJ. The effect of acute hyperglycaemia on the retinal circulation of the normal cat. Diabetologia 1980; 18: 233-7.

11 Ernest JT, Goldstick TK, Engerman RL. Hyperglycemia impairs retinal oxygen autoregulation in normal and diabetic dogs. Invest Ophthalmol Vis Sci 1983; 24: 985-9.

12 Read JS, Goldstick TK, Raichand M, Petersen AC. Hyperglycemia and the retinal microcirculation in man. Invest Ophthalmol Vis Sci 1980; 19 (suppl: ARVO abstr): 168.

13 Kohner EM, Hamilton AM, Saunders SJ, Sutcliffe BA, Bulpitt CJ: The retinal blood flow in diabetes. Diabetologia 1975; 11 : 27-33.

14 Yoshida A, Feke GT, Morales-Stoppello J, Collas GD, Goger DG, Wallace J. Retinal blood flow alterations during progress of diabetic retinopathy. Arch Ophthalmol 1983; 101: 225-7.

15 Feke GT, Tagawa H, Yoshida A, et al. Retinal circulatory changes related to retinopathy progression in insulin dependent diabetes mellitus. Ophthalmology 1985; 92: 1517-22.

16 Fallon TJ, Chowiencyzk P, Kohner EM. Measurement of retinal blood flow in diabetes by the blue-light entoptic phenomenon. $\mathrm{Br}$ J Ophthalmol 1986; 70: 43-6.

17 Jütte A. Über die Erweiterung der Netzhautvenen bei jugendlischen Diabetikern. Diabetische Angiopathie. Berlin: Akademie, 1964: 13-9.
18 Skovborg F, Nielsen Aa V, Lauritzen E, Hartkopp O. Diameters of the retinal vessels in diabetic and normal subjects. Diabetes 1969; 18: 292-8.

19 Wallace J. Vessel measurements in diabetic fundi. Proc $R$ Soc Med 1970; 63: 788-91

20 Grunwald JE, Riva CE, Sinclair SH, Bruckner AJ, Petrig BL. Laser doppler velocimetry study of retinal circulation in diabetes mellitus. Arch Ophthalmol 1986; 104: 991-6.

21 Brinchmann-Hansen $O$, Engvold $O$. Microphotometry of the blood column and the light streak on retinal vessels in fundus photographs. Acta Ophthalmol (Khh) 1986; 64 (suppl 179): 9-19.

22 Brinchmann-Hansen O, Heicr H, Myhre K. Fundus photography of width and intensity profiles of the blood column and the light reflex in retinal vessels. Acta Ophthalmol (Kbh) 1986;64 (suppl 179): 20-8.

23 Brinchmann-Hansen O, Myhre K, Dahl-Jørgensen K, Hanssen $\mathrm{KF}$, Sandvik L. The central light reflex of retinal arteries and veins in insulin dependent diabetic subjects. Acta Ophthalmol (Kbh) 1987; 65: 474-80.

24 Dahl-Jørgensen K, Larsen AE. HbA, determination by agar electrophoresis after elimination of labile $\mathrm{HbA}_{1}$ : a comparison with ion-exchange chromatography. Scand J Clin Lab Invest 1982; 42: 27-33.

25 Aabyholm AS. Determination of glucose in dried filter paper blood spots. Scand J Clin Lab Invest 1981; 41: 269-74

26 Behrendt T. Scanning densitometer for photographic fundus measurements. Am J Ophthalmol 1966; 62: 689-93.

27 Rhie FH, Christlieb AR, Sandor T, et al. Retinal vascular reactivity to norepinephrine and angiotension II in normals and diabetics. Diabetes 1982; 31: 1056-60.

28 Lehmann EL. Nonparametrics. Statistical methods based on ranks. San Fransisco: Holden-Day, McGraw-Hill, 1975: 316.

29 L'Esperance FA Jr. The pathologic hemodynamics of diabetic retinopathy: a theory. Am J Ophthalmol 1971; 71: 251-60.

30 Kohner EM. The problem of retinal blood flow in diabetes. Diabetes 1976; 25: (suppl 2): 839-44.

31 Wolbarsht ML, Landers III MB, Stefansson E. Vasodilation and the etiology of diabetic retinopathy: A new model. Ophthalmic Surg 1981; 12: 104-7.

32 Parving H-H, Viberti GC, Keen H, Christiansen JS, Lassen NA. Hemodynamic factors in the genesis of diabetic microangiopathy. Metabolism 1983; 32: 943-9.

33 Zatz R, Brenner BM. Pathogenesis of diabetic microangiopathy. The hemodynamic view. Am J Med 1986; 80: 443-53.

34 Ernest JT. Retinal circulation in diabetes mellitus (Editorial). Arch Ophthalmol 1986; 104: 986-8.

35 Larsen HW. Diabetic retinopathy. An ophthalmoscopic study with a discussion of the morphological changes and the pathogenetic factors in the disease. Copenhagen: Munksgaard Lange, Maxwell Springer, 1960: 27.

36 Hickam JB, Frayser R. Studies of retinal circulation in man. Observations on vessel diameter, arteriovenous oxygen difference, and mean circulation time. Circulation 1966; 33: 302-16.

37 Sieker HO, Hickam JB. Normal and impaired retinal vascular reactivity. Circulation 1953; 7: 79-83.

38 Grunwald JE, Riva CE, Brucker AJ, Sinclair SH, Petrig BL. Altered retinal vascular response to $100 \%$ oxygen breathing in diabetes mellitus. Ophthalmology 1984; 91: 1447-52.

39 Wise GN, Dollery CT, Henkind P. Pressure and flow measurements in retinal vessels. In: Wise GN, Dollery CT, Henkind P, eds. Retinal circulation. New York, Evanston, San Francisco, London: Harper and Row, 1971; 100-1.

40 Grunwald JE, Riva CE, Petrig BL, Sinclair SH, Brucker AJ. Effect of pure $\mathrm{O}_{2}$-breathing on retinal blood flow in normals and in patients with background diabetic retinopathy. Curr Eye Res 1984; 3: 239-41.

41 Riva CE, Grunwald JE, Sinclair SH, Petrig BL. Blood velocity and volumetric flow rate in human retinal vessels. Invest Ophthalmol Vis Sci 1985; 26: 1124-32. 
42 Brinchmann-Hansen $O$. Engvold $O$. The light streak on retinal vessels. I. A theoretical modelling of the reflex width. Acta Ophthalmol (Kbh) 1986; 64 (suppl 179): 38-45.

43 Brinchmann-Hansen $O$, Engvold $O$. The light streak on retina vessels. II. A theoretical modelling of the reflex intensity. Acta Ophthalmol (Kbh) 1986; 64 (suppl 179): 46-52.

44 Evan-Wong LA. Davidson RJ. Raised Coulter mean corpuscular volume in diabetic ketoacidosis, and its underlying association with marked plasma hyperosmolarity. J Clin Pathol 1983: 36: $334-6$.
45 Bock HA. Fluckiger R, Berger W. Real and artefactual erythrocyte swelling in hyperglycemia. Diabetologia $1985 ; 28: 335-8$.

46 Almer L-O, Pandolfi M. Fibrinolysis and diabetic retinopathy. Diabetes 1976; 25 (suppl 2): 807-10.

47 McMillan DE. Plasma protein changes, blood viscosity, and diabetic microangiopathy. Diabetes 1976: 25 (suppl 2): 858-64.

Accepted for publication 26 June 1987. 